\title{
Psychological impact of sociodemographic factors and medical conditions in older adults during the COVID-19 pandemic in Mexico
}

\author{
Alejandro González-González, 'Aldebarán Toledo-Fernández,' Héctor Romo-Parra, 'Ernesto Reyes-Zamorano, \\ Diana Betancourt-Ocampo
}

Universidad Anáhuac México Facultad de Psicología, Ciudad de México, México

\section{Correspondence:}

Dra. Diana Betancourt Ocampo

Facultad de Psicología, Universidad

Anáhuac México - Campus Norte.

Universidad Anáhuac No. 46,

Lomas Anáhuac

52786 Huixquilucan,

Estado de México

México.

Email: diana.betancour @anahuac.mx

Received: 12 June 2020

Accepted: 3 September 2020

Citation:

González-González, A., ToledoFernández, A., Romo-Parra, H., ReyesZamorano, E., \& Betancourt-Ocampo, D. (2020). Psychological impact of sociodemographic factors and medical conditions in older adults during the COVID-19 pandemic in Mexico. Salud Mental, 43(6), 293-301.

DOI: $10.17711 /$ SM.0185-3325.2020.040

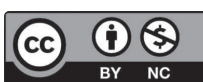

\begin{abstract}
Introduction. Older adults are not only at a higher medical risk during the COVID-19 pandemic, but they may also be a group particularly vulnerable to mental health diminishing. Objective. To analyze the effect of some sociodemographic factors (sex and age) and medical conditions (diabetes and hypertension) on mental health and concerns about COVID-19 in a sample of older adults. Method. A non-probabilistic sample of 2,992 older adults (37.7\% men and $62.3 \%$ women) was selected, with an average age of 70.45 years $(S D=7.31)$. Participants were given the Impact of Event Scale-6 (IES-6), the Patient Health Questionnaire (PHQ-9), the Generalized Anxiety Disorder-7 (GAD-7), a questionnaire of concerns about COVID-19, and a sociodemographic questionnaire. Participants' answers were captured via Google Forms. Results. The results showed that women had greater concerns about COVID-19 than men. The findings in general showed significant effects, with women showing higher scores in depressive symptoms, anxiety, and greater stress generated in addition by the impact of the event. Differences concerning event-related stress and depression were found in relation to subgroups by age. Discussion and conclusion. These finding could serve for the planning and development of strategies that provide attention to the mental health of this population group.
\end{abstract}

Keywords: Older adults, depression, anxiety, stress, COVID-19.

\section{RESUMEN}

Introducción. Los adultos mayores no sólo presentan un mayor riesgo médico durante la pandemia de COVID-19, sino que también pueden ser particularmente vulnerables a la disminución de la salud mental. Objetivo. Analizar el efecto de algunos factores sociodemográficos (sexo y edad) y condiciones médicas (diabetes e hipertensión) sobre la salud mental y las preocupaciones sobre COVID-19 en una muestra de adultos mayores. Método. Se seleccionó una muestra no probabilística de 2,992 adultos mayores $(37.7 \%$ hombres y $62.3 \%$ mujeres), con una edad promedio de 70.45 años $(D E=7.31)$. Los participantes recibieron la Estala de Impacto de Evento-6, el Cuestionario de Salud del Paciente-9, el Trastorno de Ansiedad Generalizada-7, un cuestionario de preocupaciones sobre COVID-19 y un cuestionario sociodemográfico. Resultados. Las mujeres presentaron mayores preocupaciones por COVID-19 que los hombres. Las respuestas de los participantes se capturaron en Google Forms. Resultados. En general, los hallazgos mostraron efectos significativos, siendo las mujeres quienes presentaron puntuaciones más altas en síntomas depresivos y ansiedad, así como mayor estrés asociado a evento. Además, se encontraron efectos diferenciados por subgrupos de edad en relación con estrés asociado a evento y síntomas depresivos. Discusión y conclusión. Estos hallazgos pudieran ser útiles para planificar y desarrollar estrategias que brinden atención a la salud mental de este grupo de población.

Palabras clave: Adultos mayores, depresión, ansiedad, estrés, COVID-19. 


\section{INTRODUCTION}

At the end of 2019, and according to official World Health Organization data (WHO, 2020a), a new virus, called SARS-CoV-2, appeared in mainland China, specifically in Wuhan city (Hubei province). By January 7, 2020, Chinese scientists had successfully genetically sequenced it, enabling the rapid development of real-time RT-PCR diagnostic tests (Wang, Horby, Hayden, \& Gao, 2020). However, this pandemic not only represents a challenge in terms of physical health, but also involves repercussions on the mental health of individuals. There are related to the need to maintain social isolation or distancing and which, in some way, represents a risk for the development of stress, anxiety, depression, violence, and other mental health disorders (Beaglehole et al., 2018; Brooks et al., 2020; Rubin \& Wessely, 2020; Reynolds et al., 2008).

According to Ramos (2020), this epidemic contrasts with those of the severe acute respiratory syndrome (SARS-CoV), occurred in 2002-2003, and the Middle East respiratory syndrome (MERS-CoV), detected in the Arabian Peninsula in 2013, in that the case fatality rate of COVID-19 is around $3 \%$, while for SARS-CoV and MERS-CoV it is approximately $10 \%$ and $34 \%$, respectively. However, it has been observed that case fatality rates vary, according to various conditions such as: age, tobacco use, obesity, and comorbidity with some conditions such as hypertension and diabetes (Liu, Gayle, Wilder-Smith, \& Rocklöv, 2020; Yin \& Wunderink, 2018). So, the case fatality rates are variable in each country, particularly in risk or vulnerable populations. In the case of this pandemic, those who present any of the aforementioned conditions, or in their case, older adults, tend to have more adverse and unfortunate consequences, both in terms of their physical health, where the prognosis for recovery is complicated, as in their mental health, or in the psychological consequences that they usually present (Guo et al., 2020).

In this disease, the onset of symptoms occurs approximately three to six days after exposure, with an average incubation of five days (Chan et al., 2020; Li et al., 2020). Although most of the infections reported by COVID-19 are not serious, there is data suggesting that $30 \%$ of hospitalized patients may require intensive care. It is important to note that most fatal cases of COVID-19 occurred in patients with pre-existing comorbidities (Márquez-Díaz et al., 2020).

In Mexico, the first case of coronavirus was confirmed on February 28th, when 85,403 confirmed cases of COVID-19 and 2,924 deaths had been reported until then worldwide. The case fatality rate worldwide was $3.42 \%$, with a proportion of severe cases of $9.65 \%$. Until then, cases had been reported in 53 countries outside of China, in six regions of the World Health Organization (2020b): America, Europe, Southeast Asia, Eastern Mediterranean, Western Pacific, and Africa (Secretaría de Salud, 2020). As of February 29, Mexico was below the United States (62) and
Canada (14), but above Brazil, who only had a single case at that time. However, as of the writing of this document, Mexico has exceeded the barrier of 130,000 confirmed cases, with a total of 15,357 deaths and alarmingly observing a fatality rate $12 \%$, higher than the world average, which is significant and worrying.

The government of Mexico adopted a surveillance strategy for cases affected by COVID-19, within which hygiene-related measures and preventive measures regarding physical contact were proposed. These strategies apply to the general population (Ramos, 2020); however, it should not be forgotten that the population of older adults represents a vulnerable group, due to its particular characteristics.

Regarding the population of older adults, in Mexico, as in the rest of the world, the population pyramid is being reversed and the proportion of older adults is growing more and more, thanks to the increase in life expectancy (CEPAL, Naciones Unidas, 2012). The latest data available indicates that 15.4 million people aged 60 or over reside in our country (Instituto Nacional de Estadística y Geografía, 2018); although, in general terms, most older adults report good health, it is undeniable that a disability or chronic condition typical of age is more likely to occur at this stage of life (CEPAL, Naciones Unidas, 2012). Furthermore, the presence of comorbidities in this population cannot be forgotten, being the most frequent for instance, diabetes mellitus, hypercholesterolemia, hypertension, and obesity (Secretaría de Salud \& Instituto Nacional de Salud Pública, 2016).

In addition to this, the mental health of older adults represents another concern for the Health Sector in all countries. In Mexico, approximately $15 \%$ of people over 60 years of age suffer from a mental disorder. According to various sources (Blazer, 2003; Cole \& Dendukuri, 2003; Djernes, 2006; World Health Organization, 2017; Riedel-Heller, Busse, \& Angermever, 2006; Wetherell, Maser, $\&$ van Balkom, 2005), depression and anxiety are the two most common mental health problems in the elderly population. In the case of depression, the WHO (2017) suggests that it is found more frequently in the older adult population, particularly in the 60-64 age group. Regarding anxiety, the WHO report (2017) explains that prevalence rates do not vary substantially between age groups, however, there is an observable trend towards a higher prevalence among older age groups. In both conditions, a higher prevalence is found in women compared to men (World Health Organization, 2017). In addition to the data provided by the WHO (2017), there are several studies (Naveen, Goel, Dwivedi, \& Hassan, 2020; Reddy et al., 2012; Wang et al., 2019) that report that there is a significant number of older adults who have symptoms of depression, specifically in older adults, and that women are those who have a greater propensity to present this problem.

Recent studies (Chireh, Li, \& D'Arcy, 2019; Naveen et al., 2020; Rotella \& Mannucci, 2013; Seldenrijk et al., 
2015; Vancampfort et al., 2016; Wang et al., 2019) provide evidence of comorbidity between depression and some health problems such as diabetes, hypertension, and cardiovascular problems. In this regard, Boulé et al. (2005) and Musen et al. (2008) explain that high glucose levels can increase the levels of brain neurotransmitters associated with an elevated risk of depressive symptoms. Poulsen and Pachana (2012) found that older adults with diabetes had significantly higher levels of depression and anxiety compared to older adults without diabetes.

Fiske, Wetherell and Gatz (2009) conducted a review of depression in older adults. They suggest that biological factors become very important in adulthood to present depression, but these biological factors are obviously present since they are associated with different physical diseases typical of age (for example, cardiovascular diseases, and diabetes). Along these lines, the authors mention that the onset and maintenance of depression at the end of life can be understood as an interaction between certain vulnerabilities, including genetic factors, cognitive aspects and neurobiological changes associated with age, as well as the stressful events that usually occur more often at this stage of life. On the other hand, Fiske et al. (2009) indicate that other explanations about the development of depression in older adults suggest that stressful events (for example, functional and / or cognitive limitations) become frequent in old age, which can trigger an increase in negative self-worth. Likewise, Fieske et al. (2009) explain that many older adults also experience problems with the reduction of social contacts and social isolation, which generally worse quality of life, in their state of mental and physical health, cognitive decline and increased mortality.

All in all, from the lines above, there are several factors that explain the presence of depression and anxiety in older adults. However, the situation that is being experienced today with the COVID-19 pandemic is, by itself, a factor that may favor the presence of these diseases. Further, Brooks (2020) conducted a review of various findings in similar events and found that quarantine caused a series of negative psychological effects, including symptoms of post-traumatic stress, anger, confusion, fear, anger, pain, and anxiety-induced insomnia. Likewise, the author mentions that some of the additional stressors during and after quarantine included stigma, loss of finances, boredom, and lack of supplies and information (Brooks, 2020).

The literature review allows us to understand the need for evidence regarding the effects of this pandemic, in specific countries and groups. Therefore, the present study seeks to analyze the effect of some sociodemographic factors (sex and age) and medical conditions (diabetes and hypertension) on mental health and concerns about COVID-19 in a sample of older adults in order to have elements that allow the development of care strategies for this type of phenomenon.

\section{METHOD}

\section{Design of the study}

Analytical cross-sectional.

\section{Participants}

According to the State Population Council of the Estado de México, a million 807 thousand 74 older adults resided in the state in 2019, which accounts for the universe of the study. If the sample size is calculated at a $95 \%$ confidence, a sample of 2,960 participants is obtained. Therefore, for the present study a non-probabilistic sample of 2,992 older adults was used. They were residents of 19 regions of the Estado de México, of which, $37.7 \%$ were men and $62.3 \%$ women, from 60 to 100 years of age $(M=70.45, S D=7.31)$. As can be seen in Table 1, more than half of the participants indicated elementary school as their last educational grade, and the highest percentage indicated that they were married. Regarding occupation, the highest proportion of participants reported that they were engaged in household activities and, secondly, those participants who mentioned being unemployed were found.

\section{Measurements}

A sociodemographic questionnaire was used, which included items about sex, age, education, relationship status, occupation, and current medical diagnosis (any of the fol-

Table 1

Distribution of participants by level of education, marital status and occupation

\begin{tabular}{lrr}
\hline & $f$ & $\%$ \\
\hline Education & & \\
No studies & 473 & 16.0 \\
Elementary school & 1765 & 59.6 \\
Junior high school & 425 & 14.4 \\
High school & 92 & 3.1 \\
Technician & 106 & 3.6 \\
Bachelor's degree & 94 & 3.2 \\
Master's/Specialty & 4 & .1 \\
Doctorate & 2 & .1 \\
Marital status & & \\
Single & 192 & 6.5 \\
Married & 1962 & 66.3 \\
Domestic partnership & 67 & 2.3 \\
Divorced/Separated & 142 & 4.8 \\
Widowed & 598 & 20.2 \\
Occupation & & \\
Unemployed & 478 & 16.1 \\
Retired & 419 & 14.2 \\
Employed & 373 & 12.6 \\
Housekeeping & 1691 & 57.1 \\
\hline
\end{tabular}


lowing: hypertension, diabetes, cancer, respiratory diseases, autoimmune disease or immunosuppression, obesity, and/or dyslipidemia).

In addition, the Impact of Event Scale-6 (IES-6,) was applied, which, is a brief form of the widely used Impact of Event Scale-revised (Weiss, 2007), which assesses self-report of post-traumatic stress reactions to specific events. The IES-6 includes two items for each of the dimensions of post-traumatic stress: intrusion, avoidance, and hyperarousal, and five response options ranging from 0 ("Not at all") to 4 ("Extremely"). A total score is computed, with higher scores indicating more severe event-related stress (Thoresen et al., 2010).

For this study, we used corresponding Spanish-translated items (Caamaño et al., 2011), and we instructed respondents to answer them considering the COVID-19 pandemic as the potentially stressful event, as follows: "Some people often experience difficulties during stressful events. In the following statements, think about the last seven days and how stressful the situation we are living due to the coronavirus pandemic has been for you."

The Patient Health Questionnaire (PHQ-9) was also used. This self-administered 9-item scale inquires the respondent about specific depressive symptoms corresponding to DSM-IV criteria in the last two weeks, according to a Likert scale with 0 -to-3 values. A total score is computed, with upper values indicating a higher severity of depression, which can be ranked as follows: $0-4=$ none, $5-9=$ mild, $10-$ $14=$ moderate, $15-19=$ moderately severe, $20-27=$ severe (Kroenke, Spitzer, \& Williams, 2001). The PHQ-9 is a very common scale in clinical research worldwide; evidence of its validity has been reported for Latin American and Mexican populations (Donlan \& Lee, 2010; Familiar et al., 2014), and it has been used in online surveys (Wang, Cho, \& Kim, 2018; Sierra-Aparicio, Magaña-Quijano, Vargas-Quiñones, Martínez-García, \& Toledo-Fernández, 2019).

The Generalized Anxiety Disorder-7 (GAD-7) scale was applied, which was developed to assess general anxiety disorder following the DSM-IV symptom criteria (Spitzer, Kroenke, Williams, \& Löwe, 2006) and can be used to evaluate other forms of anxiety (Plummer, Manea, Trepel, \& McMillan, 2016) . The GAD-7 is a seven-item self-administered scale; just like the PHQ-9, the GAD-7 has 0-to-3 response options, with a total score between 0-21. Higher scores indicate higher severity of anxiety, with the following ordinal values: $0-4=$ minimal, $5-9=$ mild, $10-14=\bmod -$ erate, $15-21=$ severe. Values of good internal consistency and validity have been reported for Mexican samples (Castro Silva et al., 2017; García-Campayo et al., 2009). This scale has been used in online surveys (Parkerson, Thibodeau, Brandt, Zvolensky, \& Asmundson, 2015).

The last instrument used was the Questionnaire of concerns about COVID-19, which consists of 12 items elaborated ex profeso to explore different concerns regarding the COVID-19 pandemic, specifically: perception of utility and adherence to measures of hygiene and social distancing, news information seeking and trusting, respondent's or a family member's concern of becoming infected, concern about the financial and security status of their social context, perception of impairment in daily-living due to the pandemic, and family awareness of the respondent during the pandemic. This instrument's design was based on the one developed by Wang, Pan, et al. (2020) as an example. Participants were instructed to respond to each of these questions in a 0 -to10 scale. The granulation of the scale was established in this fashion in order to allow for a more continuous variability of the responses, for each item was considered independently in the main analyses.

\section{Procedure}

The instruments' administration, via telephone, and data recollection was under the support of the Dirección de Bienestar del Adulto Mayor del Estado de México. They provided staff for the administration of the instruments, who captured participants' responses in an online format (Google Forms). To choose the participants, it was taken into consideration that they were over 60 years old and that they had cognitive clearness to be able to answer the instrument. Participants were chosen from a census from the Older Adult Wellness Management of the Estado de México, and staff from this institution decided which adults were to be contacted. Initially, the Older Adult Wellness Management generated a list of 3,000 older adults, from which, just eight refused to answer the instruments. Older adults were called by phone and explained the purpose of the study and asked to report if they understood the information about their participation in the study and to say if they agreed to participate in the study. Adults who agreed to participate in the study were asked a couple of questions to assess their spatial-temporal location and to ensure their cognitive clarity and that they might be able to answer the study instruments. In addition, the criteria and experience of the interviewer were considered (because they are professionals who work daily with this population), to determine if the older adults were consistently answering each of the questions, the interviewers were instructed that they could interrupt the interview if they considered that there were inconsistencies or incongruities in the responses of participants. It is important to point out that the information recollection was carried out for a week (April 9-17), three weeks after the Federal Government implemented preventive measures of physical isolation, a period named Phase Two.

\section{Ethical considerations}

All principles from the Declaration of Helsinki were followed. All participants were provided with information regarding the objectives of the study, the subject-matter 
Table 2

Distribution of participants by medical conditions by sex

\begin{tabular}{|c|c|c|c|c|}
\hline & \multicolumn{2}{|c|}{$\begin{array}{c}\text { Men } \\
(n=1101)\end{array}$} & \multicolumn{2}{|c|}{$\begin{array}{c}\text { Women } \\
(n=1827)\end{array}$} \\
\hline & Presence \% & Absence \% & Presence \% & Absence \% \\
\hline Hypertension & 37.3 & 62.7 & 43.8 & 56.2 \\
\hline Diabetes & 27.0 & 73.0 & 29.3 & 70.7 \\
\hline Cancer & .9 & 99.1 & .6 & 99.4 \\
\hline Respiratory disease & 3.2 & 96.8 & 3.7 & 96.3 \\
\hline Autoimmune disease & 2.7 & 97.3 & 4.4 & 95.6 \\
\hline Obesity & 3.4 & 96.6 & 3.8 & 96.2 \\
\hline Dyslipidemia & 5.2 & 94.8 & 6.5 & 93.5 \\
\hline
\end{tabular}

addressed by the questions, voluntariness, and confidentiality of participation, and the institutions involved in the implementation of the study. Before starting the Research Bioethics Committee from the Health Sciences Faculty, Anahuac University. Number 202003 under the registration CONBIOETICA-15-CEI-004-20160729 survey, individuals were asked to provide their consent.

\section{RESULTS}

First, from the data collected, we look for the medical conditions that would have been diagnosed in our sample. It is of note that $39.1 \%$ (1144) of adults indicated that they did not currently have any of the conditions listed in Table 2 . As seen in Table 2, the two conditions that were found most frequently were hypertension and diabetes, where in addition in both cases the proportion of women was higher.

To determine if there were significant differences in each of the aspects regarding concerns about COVID-19 by sex, Student's t-tests were performed for independent sam- ples. The results showed significant differences in six of the 12 aspects evaluated (Table 3 ), where women have followed hygiene measures as well as measures of physical distance / isolation more compared to men; also, women see more usefulness in these than men. In addition, significant differences were found in the COVID-19 contagion concern indicators, where, like the previous indicators, it was women who presented a greater concern about contagion, both for them and their relatives, in contrast to the men. However, something that drew attention to these indicators is that the score was higher, that is, a greater concern about the contagion of a relative than the contagion of the adults themselves.

ANOVA tests were performed to compare the main effects by type of illness, age group and sex of older adults on the perceived impact of the event (COVID-19 pandemic), depressive symptoms, and anxiety. Regarding the type of disease, only hypertension and diabetes were considered because they were the ones that occurred most frequently, and so indicator was created where there could be adults without the presence of any of these conditions, only one of these or both conditions.

Table 3

Comparison of means in concerns about COVID-19 between men and women

\begin{tabular}{|c|c|c|c|c|c|c|}
\hline & \multicolumn{2}{|c|}{ Men } & \multicolumn{2}{|c|}{ Women } & \multirow[b]{2}{*}{$t$} & \multirow[b]{2}{*}{$d$} \\
\hline & $M$ & $S D$ & $M$ & $S D$ & & \\
\hline 1. Compliance of hygiene measures for the prevention of coronavirus & 8.47 & 1.80 & 8.81 & 1.55 & $-5.31^{*}$ & -.20 \\
\hline 2. Usefulness of hygiene measures & 8.73 & 1.65 & 9.01 & 1.40 & $-4.73^{*}$ & -.18 \\
\hline 3. Compliance with distancing / physical isolation measures & 8.28 & 2.00 & 8.68 & 1.68 & $-5.59^{*}$ & -.21 \\
\hline 4. Usefulness of physical isolation / distancing measures & 8.63 & 1.72 & 8.90 & 1.52 & $-4.29^{*}$ & -.16 \\
\hline 5. Frequency of search for information & 7.54 & 2.40 & 7.65 & 2.38 & -1.26 & NS \\
\hline 6. Confidence level on the information received & 7.37 & 2.35 & 7.48 & 2.29 & -1.27 & NS \\
\hline 7. Concern about becoming infected & 8.01 & 2.38 & 8.31 & 2.25 & $-3.04^{*}$ & -.12 \\
\hline 8. Concern about a family member becoming infected & 8.47 & 2.09 & 8.70 & 1.98 & $-3.05^{\star *}$ & -.11 \\
\hline 9. Concern about their economic situation due to the pandemic & 8.91 & 1.72 & 8.90 & 1.70 & .10 & NS \\
\hline 10. Concern about security in their area due to the pandemic & 8.22 & 2.10 & 8.31 & 2.06 & -.14 & NS \\
\hline 11. Level of affectation of their life by the pandemic & 8.07 & 2.28 & 8.07 & 2.29 & -.10 & NS \\
\hline 12. Family's level of attention to their contingency needs & 8.84 & 1.85 & 8.86 & 1.80 & -.37 & NS \\
\hline
\end{tabular}

Notes: ${ }^{*} p<.001,{ }^{* *} p<.010 ;$ NS = Not significant, values $<.10$ 
Table 4

Comparison of means of the impact of the event by COVID-19 by condition, age group and sex

\begin{tabular}{|c|c|c|c|c|c|}
\hline & & $\begin{array}{c}\text { Without } \\
\text { diagnostic of } \\
\text { Hypertension/ } \\
\text { Diabetes }\end{array}$ & Hypertension & Diabetes & Both ailments \\
\hline Age group & Sex & $M(S D)$ & $M(S D)$ & $M(S D)$ & $M(S D)$ \\
\hline \multirow[t]{2}{*}{60 to 69 years } & Men & $3.33(3.85)$ & $3.77(4.17)$ & $3.95(4.60)$ & $4.72(4.13)$ \\
\hline & Women & $4.40(4.06)$ & $4.07(4.06)$ & $4.62(4.07)$ & $4.24(3.94)$ \\
\hline \multirow[t]{2}{*}{70 to 79 years } & Men & $3.54(3.67)$ & $3.12(3.03)$ & $4.03(4.09)$ & $3.80(3.08)$ \\
\hline & Women & $4.54(3.89)$ & $5.02(3.98)$ & $5.50(4.47)$ & $4.82(3.96)$ \\
\hline \multirow[t]{2}{*}{80 years or more } & Men & $3.67(3.36)$ & $3.14(2.68)$ & $3.35(2.49)$ & $3.26(3.11)$ \\
\hline & Women & $4.22(3.54)$ & $4.05(3.99)$ & $4.87(3.14)$ & $4.48(4.51)$ \\
\hline
\end{tabular}

Concerning the effect on the perception of the impact of the event (COVID-19 pandemic), the findings showed (Table 4) significant effects due to the interaction [F (1, 2922) $=1717.44, p<.001, \eta=.37$, as well as by sex $(\mathrm{F}=3.48, p<.050, \eta=.07)$ and by the interaction of age groups and $\operatorname{sex}(\mathrm{F}=3.48, p<.050, \eta=.02)$, but there were no significant effects with the type of condition $(\mathrm{F}=1.01$, $p>.050)$. In other words, these findings indicate that it was the women in the 70 to 79 -year-old group who presented greater stress due to the impact of the event.

In relation to depressive symptoms (Table 5), the results indicate significant effects on the interaction $[\mathrm{F}(1$, 2922) $=1031.94, p<.001, \eta=.26]$; in particular, the findings showed significant effects by the interaction of type of disease and $\operatorname{sex}(\mathrm{F}=3.02, p<.050, \eta=.03)$, as well as a significant effect by age group and $\operatorname{sex}(\mathrm{F}=3.08, p<.050$, $\eta=.02$ ), where women with both hypertension and diabetes had higher scores on depressive symptoms. In the same way, the women in the group of 80 years or older were the ones who presented higher scores in depressive symptoms.

About anxiety (Table 6), we found a significant effect of the interaction $[\mathrm{F}(1,2922)=1097.88, p<.001, \eta=.27]$. Effects were found by $\operatorname{sex}(\mathrm{F}=10.81, p<.001, \eta=.04)$ and by disease category $(\mathrm{F}=4.10, p<.010, \eta=.04)$, specifically women presented higher scores in anxiety than men, and older adults with diabetes and without hypertension, were those who presented higher scores in anxiety, compared to the other conditions.

\section{DISCUSSION AND CONCLUSION}

The present study aimed to evaluate some variables of the mental health of older adults, specifically anxiety and depression related to the health contingency due to the COVID-19 pandemic in Mexico, which implies measures of social distancing in this population.

Respecting the presence of the different health conditions evaluated, it can be said that, fortunately, the proportion of older adults who reported not presenting them was higher. Hypertension and diabetes were the conditions that were reported most frequently. It was noteworthy that in both conditions (hypertension and diabetes), the proportion of women who reported presenting them was higher compared to men. This result does not entirely agree with the data reported by ENSANUT (Secretaría de Salud \& Instituto Nacional de Salud Pública, 2016) since, in this survey, they indicate that in this age group diabetes occurs more in women, but hypertension is more often present in men. Likewise, in both obesity and dyslipidemia, the proportion reported in the present study is much lower than that reported in this age group in ENSANUT (Secretaría de Salud

Table 5

Comparison of means of depressive symptoms by disease, age group and sex

\begin{tabular}{|c|c|c|c|c|c|}
\hline & & $\begin{array}{c}\text { Without diagnostic } \\
\text { of Hypertension/ } \\
\text { Diabetes }\end{array}$ & Hypertension & Diabetes & Both ailments \\
\hline Age group & Sex & $M(S D)$ & $M(S D)$ & $M(S D)$ & $M(S D)$ \\
\hline \multirow[t]{2}{*}{60 to 69 years } & Men & $1.94(3.05)$ & $2.16(3.31)$ & $2.48(3.68)$ & $3.20(3.64)$ \\
\hline & Women & $2.23(3.12)$ & $2.34(3.33)$ & $2.69(3.41)$ & $2.51(3.05)$ \\
\hline \multirow[t]{2}{*}{70 to 79 years } & Men & $2.11(3.06)$ & $1.65(3.34)$ & $2.40(3.78)$ & $2.65(3.69)$ \\
\hline & Women & $3.09(3.69)$ & 3.09 (3.95) & $3.51(4.53)$ & $2.47(3.08)$ \\
\hline \multirow[t]{2}{*}{80 years or more } & Men & $2.35(3.86)$ & $2.85(3.67)$ & $4.05(3.83)$ & $3.76(4.05)$ \\
\hline & Women & $3.51(3.83)$ & $2.65(3.98)$ & $4.87(5.57)$ & $2.91(3.83)$ \\
\hline
\end{tabular}


Table 6

Comparison of anxiety means by illness, age group and sex

\begin{tabular}{|c|c|c|c|c|c|}
\hline & & $\begin{array}{c}\text { Without diagnostic } \\
\text { of Hypertension/ } \\
\text { Diabetes }\end{array}$ & Hypertension & Diabetes & Both ailments \\
\hline Age group & Sex & $M(S D)$ & $M(S D)$ & $M(S D)$ & $M(S D)$ \\
\hline \multirow[t]{2}{*}{60 to 69 years } & Men & $2.04(3.05)$ & $2.57(3.28)$ & $2.58(3.69)$ & $3.08(3.22)$ \\
\hline & Women & $2.38(2.90)$ & $2.61(3.31)$ & $3.11(3.35)$ & $2.72(3.01)$ \\
\hline \multirow[t]{2}{*}{70 to 79 years } & Men & $2.22(3.06)$ & $1.82(2.51)$ & $2.38(3.59)$ & $2.29(3.18)$ \\
\hline & Women & $2.80(3.09)$ & $3.30(3.82)$ & $2.83(3.95)$ & $2.68(3.04)$ \\
\hline \multirow[t]{2}{*}{80 years or more } & Men & $1.85(2.81)$ & $2.20(2.96)$ & $3.35(3.34)$ & $2.76(2.95)$ \\
\hline & Women & $2.80(3.42)$ & $2.71(3.16)$ & $4.16(4.37)$ & $3.48(4.51)$ \\
\hline
\end{tabular}

\& Instituto Nacional de Salud Pública, 2016). It is of note that, in this study, older adults were asked to report whether they had a diagnosis by a doctor of the conditions evaluated, which could be the explanation for the differences found and which, furthermore, does not necessarily imply that they do not have the condition. Even with the differences found, it can be said that a significant number of older adults present these factors that can aggravate the disease due to a COVID-19 infection.

About the concern that our sample refers to the presence of the COVID-19 pandemic, we can say that there are differences between men and women in six of the twelve aspects evaluated. Here we found that in the group of women there are higher levels of concern for the pandemic, of attachment to the recommendations, and of recognition about the usefulness of the measures implemented by health authorities, which seems to be related to cultural aspects of the protective role that women play in Latino societies (Sesento, 2015). Although we should not lose sight of considering that the observed averages for both groups are not low. In addition to this, it is interesting that for both men and women there is a greater concern about a member of their family becoming ill, even above concern for themselves, which denotes in certain form, the role that the family still plays in societies like ours (García-Méndez, Rivera-Aragón, Díaz-Loving, \& Reyes-Lagunes, 2015).

With reference to the effect of sex, age, and medical condition (hypertension and/or diabetes) on the psychological factors evaluated in the situation of the COVID-19 pandemic, the results of the present study showed that it is women who present the highest depression symptoms, and anxiety and who perceive a greater impact due to the situation of the pandemic in contrast to men, which agrees with previous literature (Naveen et al., 2020; World Health Organization, 2017; Reddy et al., 2012; Wang et al., 2019) In relation to how much depression like anxiety, are ailments that occur more frequently in women than in men. Likewise, previous studies indicate that age is also a factor that may increase the probability of presenting depressive symptoms, which is consistent with the findings of the present study, where older women (80 years or older) were those who presented higher scores.

Previous evidence indicates that there is comorbidity between depression and some chronic diseases such as diabetes, hypertension, and cardiovascular problems (Chireh et al., 2019; Naveen et al., 2020; Rotella \& Mannucci, 2013; Seldenrijk et al., 2015; Vancampfort et al., 2016; Wang et al., 2019), which is consistent with the findings found in the present investigation, since, when analyzing the effect that the type of condition had on depressive symptoms, the results indicated that older adults (specifically women) with both diabetes and hypertension were the ones who presented the most depressive symptoms. There are studies (Boulé et al., 2005; Musen et al., 2008) suggesting a relationship between diabetes and depressive symptoms, this due to the fact that high glucose levels increase the levels of brain neurotransmitters associated with an elevated risk of depressive symptoms.

Fiske et al. (2009) carried out a review on depression in older adults. These authors suggest that, both at the beginning and in the maintenance of depression in the older adult population, there are various factors associated with the presence of this (e. g., genetic, cognitive factors and neurobiological changes). However, the perception of stressful events, as well as the reduction of social contact, may trigger an increase in negative valuations in older adults, which affects the state of mental and physical health. Although the present investigation did not analyze the relationship between variables such as depressive symptoms, anxiety, and stress generated by the impact the COVID-19 pandemic, it did analyze how the presence of medical conditions such as hypertension and diabetes and, demographics factors such as sex and age, affect the perception of the stressful event. In addition, although the type of disease was not a factor that had a significant effect on the perception of the stressful event, age and sex did have that effect. This is, women of the middle group (from 70 to 79 years old) were those who presented the greatest stress generated by the pandemic.

In this way, the evidence presented here will serve for the planning and development of strategies that provide at- 
tention to the mental health of this population group, without losing sight of the fact that, though often assumed to be a vulnerable one, we may reconsider their resiliency when facing stressful situations such as this pandemic.

It is important to point out that within the limitations that the present study has, it was found that no information was obtained about previous health variables, such as, depressive symptoms, anxiety, or the use of certain medication that could affect the generalization of the findings discovered. In this same sense, it is recognized that even if the information was obtained from a significant sample of older adults, the participants' selection didn't follow a probability sampling, which could influence the external validity of the results.

\section{Funding}

None.

\section{Conflict of interest}

The authors declare they have no conflicts of interest.

\section{Contributions}

All authors participated in the conceptualization and conduction of the study. AG-G established cooperation with the recruitment site. DB-O designed the online survey and prepared the database. AG-G and DB-O drafted the manuscript and conducted statistical analyses. AT-F, HR-P and ER-Z provided critical review of the manuscript. The final version of this manuscript was approved by all authors.

\section{Acknowledgement}

The authors express their gratitude to the Dirección de Bienestar del Adulto Mayor del Estado de México for providing staff resources and contact with their beneficiaries, as part of the research chair Wellbeing of the older adults.

\section{REFERENCES}

Beaglehole, B., Mulder, R. T., Frampton, C. M., Boden, J. M., Newton-Howes, G., \& Bell, C. J. (2018). Psychological distress and psychiatric disorder after natural disasters: systematic review and meta-analysis. British Journal of Psychiatry, 213(6), 716-722. doi: 10.1192/bjp.2018.210

Blazer, D. G. (2003). Depression in late life: Review and commentary. Journal of Gerontology Series A: Biological Sciences and Medical Sciences, 58(3), M249-M265. doi: 10.1093/gerona/58.3.M249

Boulé, N. G., Weisnagel, S. J., Lakka, T. A., Tremblay, A., Bergman, R. N., Rankinen, T., ... Bouchard, C. (2005). Effects of exercise training on glucose homeostasis: The Heritage Family Study. Diabetes Care, 28(1), 108-114. doi: 10.2337/ diacare.28.1.108

Brooks, S. K., Webster, R. K., Smith, L. E., Woodland, L., Wessely, S., Greenberg, N., \& Rubin, G. J. (2020). The psychological impact of quarantine and how to reduce it: rapid review of the evidence. The Lancet, 395(10227), 912-920. doi: 10.1016/S0140-6736(20)30460-8

Caamaño W., L., Fuentes M., D., González B., L., Melipillán A., R., Sepúlveda C., M., \& Valenzuela G., E. (2011). Adaptación y validación de la versión chilena de la escala de impacto de evento-revisada (EIE-R). Revista Médica de Chile, 139(9), 1163-1168. doi: 10.4067/S0034-98872011000900008

Castro Silva, E., Benjet, C., Juárez García, F., Jurado Cárdenas, S., Lucio GómezMaqueo, M. E., \& Valencia Cruz, A. (2017). Non-suicidal self-injuries in a sample of Mexican university students. Salud Mental, 40(5), 191-199. doi: 10.17711/SM.0185-3325.2017.025

CEPAL, Naciones Unidas. (2012). Foro Internacional sobre los derechos de las personas mayores - March 26-28. Retrieved from https://www.cepal.org/es/ eventos/foro-internacional-derechos-personas-mayores

Chan, J. F.-W., Yuan, S., Kok, K.-H., To, K. K.-W., Chu, H., Yang, J., ... Yuen, K.Y. (2020). A familial cluster of pneumonia associated with the 2019 novel coronavirus indicating person-to-person transmission: a study of a family cluster. The Lancet, 395(10223), 514-523. doi: 10.1016/S0140- 6736(20)30154-9

Chireh, B., Li, M., \& D'Arcy, C. (2019). Diabetes increases the risk of depression: A systematic review, meta-analysis and estimates of population attributable fractions based on prospective studies. Preventive Medicine Reports, 14, 100822. doi: 10.1016/j.pmedr. 2019.100822

Cole, M.G., \& Dendukuri, N. (2003) Risk factors for depression among elderly community subjects: A systematic review and meta-analysis. The American Journal of Psychiatry, 160(6), 1147-1156. doi: 10.1176/appi.ajp.160.6.1147

Djernes, J. K. (2006) Prevalence and predictors of depression in populations of elderly: a review. Acta Psychiatrica Scandinavica, 113(5), 372-387. doi: 10.1111/j.1600-0447.2006.00770.x

Donlan, W., \& Lee, J. (2010). Screening for depression among indigenous Mexican migrant farmworkers using the Patient Health Questionnaire-9. Psychological Reports, 106(2), 419-432. doi: 10.2466/PR0.106.2.419-432

Familiar, I., Ortiz-Panoso, E., Hall, B., Vieitez, I., Romieu, I., Lopez-Ridaura, R., \& Lajous, M. (2014). Factor structure of the Spanish version of the Patient Health Questionnaire-9 in Mexican women. International Journal of Methods in Psychiatric Research, 24(1), 74-82. doi: 10.1002/mpr.1461

Fiske, A., Wetherell, J. L., \& Gatz, M. (2009). Depression in Older Adults. Annual Review of Clinical Psychology, 5, 363-389. doi: 10.1146/annurev. clinpsy.032408.153621

García-Campayo, J., Zamorano, E., Ruíz, M. A., Pardo, A., Freire, O., Pérez-Páramo, M., ... Rejas, J. (2009). Cultural adaptation into Spanish of the generalized anxiety disorder scale-7 (GAD-7) scale. European Psychiatry, 24(Supp. 1), S538. doi: 10.1016/s0924-9338(09)70771-0

García-Méndez, M., Rivera-Aragón, S., Díaz-Loving, R., \& Reyes-Lagunes, I. (2015). Continuidad y cambio en la familia. Factores intervenientes. México: Manual Moderno.

Guo, Y., Cao, Q., Hong, Z., Tan, Y., Chen, S., Jing, H., ... Yan, Y. (2020). The origin, transmission and clinical therapies on coronavirus disease 2019 (COVID-19) outbreak - an update on the status. Military Medical Research, 7(1), 11. doi: 10.1186/s40779-020-00240-0

Instituto Nacional de Estadística y Geografía. (2018). Encuesta Nacional de la Dinámica Demográfica (ENADID) 2018. Retrieved from https://www.inegi. org.mx/programas/enadid/2018/

Kroenke, K., Spitzer, R. L., \& Williams, J. B. W. (2001). The PHQ-9: Validity of a brief depression severity measure. Journal of General Internal Medicine, 16(9), 606-613. doi: 10.1046/j.1525-1497.2001.016009606.X

Li, Q., Guan, X., Wu, P., Wang, X., Zhou, L., Tong, Y., ... Feng, Z. (2020). Early transmission dynamics in Wuhan, China, of novel coronavirus-infected pneumonia. The New England Journal of Medicine, 382(13), 1199-1207. doi: 10.1056/ NEJMoa2001316

Liu, Y., Gayle, A. A., Wilder-Smith, A., \& Rocklöv, J. (2020). The reproductive number of COVID-19 is higher compared to SARS coronavirus. Journal of Travel Medicine, 27(2). doi: 10.1093/jtm/taaa021

Márquez-Díaz, F., Rojas-Flores, D. M., Cárdenas-Bravo, L., Cadena-Orea, D., PérezBarragán, E., Paredes-Ceballos, O., ... Cabrera-Rayo, A. (2020). Position of the College of Internal Medicine of Mexico on the new coronavirus, 2019. Medicina Interna de México, 36(1), 87-93. doi: 10.24245/mim. v36i1.3922

Musen, G., Simonson, D. C., Bolo, N. R., Driscoll, A., Weinger, K., Raji, A., ... Jacobson, A. M. (2008). Regional brain activation during hypoglycemia in Type 1 Diabetes. The Journal of Clinical Endocrinology \& Metabolism, 93(4), 14501457. doi: 10.1210/jc.2007-2007

Naveen, K., Goel, A. D., Dwivedi, S., \& Hassan, M. A. (2020). Adding life to years: Role of gender and social and family engagement in geriatric depression in rural areas of Northern India. Journal of Family Medicine and Primary Care, 9(2), 721-728. doi: 10.4103/jfmpc.jfmpc_1019_19 
Parkerson, H. A., Thibodeau, M. A., Brandt, C. P., Zvolensky, M. J., \& Asmundson, G. J. G. (2015). Cultural-based biases of the GAD-7. Journal of Anxiety Disorders, 31, 38-42. doi: 10.1016/j.janxdis.2015.01.005

Plummer, F., Manea, L., Trepel, D., \& McMillan, D. (2016). Screening for anxiety disorders with the GAD-7 and GAD-2: a systematic review and diagnostic metaanalysis. General Hospital Psychiatry, 39, 24-31. doi: 10.1016/j. genhosppsych.2015.11.005

Poulsen, K., \& Pachana, N. A. (2012). Depression and anxiety in older and middle-aged adults with diabetes. Australian Psychologist, 47(2), 90-97. doi: 10.1111/j.1742-9544.2010.00020.x

Ramos, C. (2020). Covid-19: la nueva enfermedad causada por un coronavirus. Salud Pública de México, 62(2), 225-227. doi: 10.21149/11276

Reddy, N. B., Pallavi, M., Reddy, N. N., Reddy, C. S., Singh, R. K., \& Pirabu, R. A. (2012). Psychological Morbidity Status Among the Rural Geriatric Population of Tamil Nadu, India: A Cross-sectional Study. Indian Journal of Psychological Medicine, 34(3), 227-231. doi: 10.4103/0253-7176.106016

Reynolds, D. L., Garay, J. R., Deamond, S. L., Moran, M. K., Gold, W., \& Styra, R. (2008). Understanding, compliance and psychological impact of the SARS quarantine experience. Epidemiology \& Infection, 136(7), 997-1007. doi: $10.1017 /$ S0950268807009156

Riedel-Heller, S. G., Busse, A., \& Angermeyer, M. C. (2006). The state of mental health in old-age across the "old" European Union - systematic review. Acta Psychiatrica Scandinavica, 113(5), 388-401. doi: 10.1111/j.16000447.2005.00632.x

Rotella, F., \& Mannucci, E. (2013). Diabetes mellitus as a risk factor for depression. A meta- analysis of longitudinal studies. Diabetes Research and Clinical Practice, 99(2), 98-104. doi: 10.1016/j.diabres.2012.11.022

Rubin, G. J., \& Wessely, S. (2020). The psychological effects of quarantining a city. BMJ, 368, m313. doi: 10.1136/bmj.m313

Secretaría de Salud, \& Instituto Nacional de Salud Pública. (2016). Encuesta Nacional de Salud y Nutrición, ENSANUT 2016. Retrieved from https://ensanut.insp.mx/encuestas/ensanut2016/doctos/informes/ ENSANUT2016ResultadosNacionales.pdf

Secretaría de Salud. (2020). Nuevo Coronavirus en el mundo COVID-19. Comunicado Técnico Diario - February 29. Retrieved from https://www. gob.mx/salud/prensa/nuevo-coronavirus-en-el-mundo-covid-19-comunicadotecnico-diario-236362

Seldenrijk, A., Vogelzangs, N., Batelaan, N. M., Wieman, I., van Schaik, D. J. F., \& Penninx, B. J. W. H. (2015). Depression, anxiety and 6-year risk of cardiovascular disease. Journal of Psychosomatic Research, 78(2), 123-129. doi: 10.1016/j.jpsychores.2014.10.007

Sesento, G. L. (2015). El papel de la mujer en el desarrollo de México. Revista Contribuciones a las Ciencias Sociales, 27. Retrieved from http://www.eumed. net/rev/cccss/2015/01/mujer.html

Sierra-Aparicio, T. A., Magaña-Quijano, B. P., Vargas-Quiñones, J., Martínez-García, B., \& Toledo-Fernández, A. (2019). Moderating effects of executive function between depression severity and work performance: a web-based cross-sectional study. Salud Mental, 42(2), 59-64. doi: 10.17711/SM.0185-3325.2019.008
Spitzer, R. L., Kroenke, K., Williams, J. B. W., \& Löwe, B. (2006). A brief measure for assessing generalized anxiety disorder: The GAD-7. Archives of Internal Medicine, 166(10), 1092-1097. doi: 10.1001/archinte.166.10.1092

Thoresen, S., Tambs, K., Hussain, A., Heir, T., Johansen, V. A., \& Bisson, J. I. (2010). Brief measure of posttraumatic stress reactions: Impact of Event Scale-6. Social Psychiatry and Psychiatric Epidemiology, 45(3), 405-412. doi: 10.1007/ s00127-009-0073-x

Vancampfort, D, Correll, C. U., Galling, B., Probst, M., De Hert, M., Ward. P. B., ... Stubbs, B. (2016). Diabetes mellitus in people with schizophrenia, bipolar disorder and major depressive disorder: a systematic review and large scale meta-analysis. World Psychiatry, 15(2), 166-174. doi: 10.1002/wps.20309

Wang, H. R., Cho, H., \& Kim, D.-J. (2018). Prevalence and correlates of comorbid depression in a nonclinical online sample with DSM-5 internet gaming disorder. Journal of Affective Disorders, 226, 1-5. doi: 10.1016/j.jad.2017.08.005

Wang, R., Bishwajit, G., Zhou, Y., Wu, X., Feng, D., Tang, S., ... Feng, Z. (2019). Intensity, frequency, duration, and volume of physical activity and its association with risk of depression in middle- and older-aged Chinese: Evidence from the China Health and Retirement Longitudinal Study, 2015. PloS One, 14(8), e0221430. doi: 10.1371/journal.pone.0221430

Wang, C., Horby, P. W., Hayden, F. G., \& Gao, G. F. (2020). A novel coronavirus outbreak of global health concern. The Lancet, 395(10223), 470-473. doi: 10.1016/S0140-6736(20)30185-9

Wang, C., Pan, R., Wan, X., Tan, Y., Xu, L., Ho, C. S., \& Ho, R. C. (2020). Immediate psychological responses and associated factors during the initial stage of the 2019 coronavirus disease (COVID-19) epidemic among the general population in China. International Journal of Environmental Research and Public Health, 17(5), 1729; doi: 10.3390/ijerph17051729

Weiss, D. S. (2007). The Impact of Event Scale: Revised. In Wilson, J. P., \& Tang, C. S.-k. (Eds.). International and cultural psychology. Cross-cultural assessment of psychological trauma and PTSD, (pp. 219-238). Springer Science + Business Media. doi: 10.1007/978-0-387-70990-1_10

Wetherell, J. L., Maser, J. D., \& van Balkom, A. (2005). Anxiety disorders in the elderly: outdated beliefs and a research agenda. Acta Psychiatrica Scandinavica, 111(6), 401-402. doi: 10.1111/j.1600-0447.2005.00545.x

World Health Organization. (2017). Depression and Other Common Mental Disorders: Global Health Estimates. Geneva: World Health Organization. Retrieved from https://apps.who.int/iris/bitstream/handle/10665/254610/WHOMSD-MER-2017.2-eng.pdf?sequence=1

World Health Organization. (2020a). Novel Coronavirus (2019-nCoV) Situation Report-1, January 21. World Health Organization. Retrieved from https://www. who.int/docs/default-source/coronaviruse/situation-reports/20200121-sitrep-12019-ncov.pdf? sfvrsn=20a99c10 4

World Health Organization. (2020b). WHO Coronavirus Disease (COVID-19) Dashboard - May 13. World Health Organization. Retrieved from https:// covid19.who.int/

Yin, Y., \& Wunderink, R. G. (2018). MERS, SARS and other coronaviruses as causes of pneumonia. Respirology, 23(2), 130-137. doi: 10.1111/resp.13196 